\title{
Effect of Integrating Statistical Concepts on Third Year Student Teachers' Academic Performance on Heredity in Biology
}

\author{
Bernard Nkwale $^{1^{*}}$ Dr. George Kasali ${ }^{2} \quad$ Peter Chipowe $^{3}$ \\ 1.Malcolm Moffat College of Education, Natural Science Department, P/B 1, Serenje, Zambia \\ 2.Copperbelt University, School of Mathematics and Natural Sciences, P.O. BOX 21692, Kitwe, Zambia \\ 3.Malcolm Moffat College of Education, Mathematics Department, P/B 1, Serenje, Zambia
}

\begin{abstract}
This study examined the effect of integrating Statistical concepts on Third year student teachers' academic performance on Heredity in Biology. The study adopted purposive sampling where 93 participants were randomly assigned into two groups, i.e. an Experimental class $(n=45)$ and a Control group $(n=48)$.Three research questions and two hypotheses guided the study. The study used a quasi-experimental pretest-posttest control group design. Data were collected using a 8 -item structured questionnaire which was used to obtain data on students' attitude towards heredity while an Achievement Test' (AT), which comprised 4 questions, was used to measure the students' performance in genetics. The two null hypotheses were tested using the Independent Sample T-test (at $\alpha=0.05$ ) while the third question was analysed using percentages. The findings from the study showed that students taught Heredity by integrating statistical concepts achieved higher scores and significantly better than those taught using conventional methods ( $\mathrm{df}=91 ; \mathrm{p}=0.001<\alpha=0.05)$. There was also no better achievement in favour of the male students compared to their female counter parts when taught by integrating the statistical concepts in the experimental group $(\mathrm{df}=43 ; \mathrm{p}=0.871>\alpha=0.05)$. It further established that students developed positive attitude towards Heredity after integrating statistical concepts in the teaching of Heredity in Biology. The study recommends among other things, that since integrating statistical concepts is found to be an effective strategy and enhanced achievement among Biology students, teachers and lecturers of this subject should accept it as one of the strategies they can use in teaching Heredity in Biology so as to enhance students' academic performance.
\end{abstract}

Keywords: effect, statistical concepts, integrating, attitude, academic performance

DOI: $10.7176 / \mathrm{JEP} / 10-20-13$

Publication date:July $31^{\text {st }} 2019$

\section{Introduction}

Biology and mathematics have been interconnected for a long time. In fact, many biological processes are described by mathematical equations and certain mathematical concepts have arisen directly from the need to describe interactions, relationships, and processes in living systems (Jungck,1997;Cohen,2004).

Statistics is a branch of Mathematics which has been applied in a number of fields (Quinonez,2014). Statistics therefore, helps us in reading, analyzing, interpreting, and making decisions using data. Understanding statistics helps in determining the meaning of statistics in Biology (Boda, 2011). The incorporation of statistics in biology helps to predict models and describe the function of biological processes at the ecological, organismal, and cellular level (Elser \& Hamilton, 2007). Based on this, the researcher would want to investigate the effect of integrating Statistical concepts on Third year student teachers' academic performance on heredity in Biology: A case of Malcolm Moffat College of Education.

\subsection{Statement of the problem}

The challenges biology educators face today are multidimensional. Firstly, biology courses generally do not emphasize the role of mathematical analysis in the description of biological data, a critical element in many major scientific discoveries. Secondly, most mathematics courses do not make a connection between mathematical concepts and applications to other fields of science (Robeva and Laubenbacher, 2009). The lack of connection between the general statistics course required for students in biology make students to perform poorly in Heredity, one of the topics in Biology. For instance, from the findings of Watt (2009) in the United States, lack of necessary mathematical knowledge and skills inevitably renders people unsuccessful in performing better in mathematical related Biology questions. Again the performance of candidates in Biology Paper 2 in Zambia has been going down with most candidates generally failing to answer in a scientific manner and have little understanding of scientific concepts. From the examiner's report, it was noted that genetics has been a problematic question for the majority of candidates. Generally the question is poorly answered and in some cases just left blank (ECZ, 2017).

As a consequence, these same candidates with limitations in Genetics end up being student teachers in Colleges of Education. This trend continues even at College level. For example, in 2017 Promotional examination in Biology performance analysis of topic by topic, of the $70 \%$ students who attempted the question 
on genetics, only $39 \%$ got the question correct. While in 2018 , of the $78 \%$ who attempted the question, only $30 \%$ got it right. The researcher attributes this poorly achieved result to lack of integrating Statistical concepts in Biology. The researcher attributes poor results to lack of statistical concepts in genetics among the student teachers,

Against this background, the researcher therefore, would want to investigate whether integrating Statistical concepts on Third year student teachers' academic performance on Heredity in Biology can change the status core.

\subsection{Scope of the study}

This study was designed to cover the entire third year Biology students of 2019 intake at Malcolm Moffat College of Education. It focused on examining the effect of integrating statistical concepts on third year student teachers' Academic Achievement on Heredity in biology. The study would also determine whether gender has any influence on Academic Achievement of students on Heredity. The study was guided by the following research questions and hypotheses:

a) What impact does integrating statistical concept have on student teachers' Academic

Achievement on Heredity in Biology?

b) What effect does gender have on students' performance on heredity in Biology?

c) What is the effect of integrating statistical concepts on students' attitude towards heredity?

$\mathbf{H O}_{1}$ : There is no significant difference between the mean achievement scores of students who are taught by integrating statistical concept in the teaching of Heredity and those who are taught without integrating statistical concepts.

$\mathbf{H O}_{2}$ : There is no significant difference between the mean achievement scores of female students and male students in genetics when taught heredity by integrating statistical concepts.

\subsection{Theoretical and methodological frameworks}

The theoretical framework informing this study is constructivism which advances the view that the teacher supports the use of the new knowledge by creating situations wherein students interact with information, using it to solve problems, discussing interpretations and answering questions as it becomes their own. However, this requires the continuous restructuring of the subject matter knowledge by the teacher which Cochran, DeRuiter and King (1993) term pedagogical content knowing. Leach and Scott (2003: 102) typify the role of the teacher within constructivism as "to introduce and support the use of new knowledge on the social plane", whilst the role of the student is to "internalize the ideas for personal use." The philosophical paradigm on which the data were collected and analysed was Positivism which states that data can be interpreted according to a procedure.

\section{Literature Review}

\begin{tabular}{|c|c|c|}
\hline $\begin{array}{c}\text { Author/ title } \\
\end{array}$ & Design & Results \\
\hline $\begin{array}{l}\text { Meleka \& Samuel (2018) The Significance } \\
\text { of Statistics in Undergraduate Biology } \\
\text { Education - A case of CBU }\end{array}$ & Survey & $\begin{array}{l}\text { From the findings and results of the } \\
\text { study, it was found that statistics is very } \\
\text { significant to undergraduate Biology } \\
\text { Education at the Copperbelt University }\end{array}$ \\
\hline $\begin{array}{l}\text { Kasongo \& Samuel (2018). Impact of } \\
\text { reducing Mathematics component in O- } \\
\text { level Biology- A case of Colleges of } \\
\text { Education in Mansa }\end{array}$ & Survey & $\begin{array}{l}\text { There is greater impact on reducing } \\
\text { Mathematics component in } \mathrm{O}-\text { level Biology } \\
\text { questions which in turn lead to poor } \\
\text { performance at College }\end{array}$ \\
\hline $\begin{array}{l}\text { Berligeri, Burrowes \& } \\
\text { Jungck(2017).Teaching Biology through } \\
\text { Statistics: Application of Statistical } \\
\text { methods in Genetics and Zoology courses. }\end{array}$ & $\begin{array}{c}\text { Quasi- } \\
\text { Experimental }\end{array}$ & $\begin{array}{l}\text { Students for Biology exhibited lack of } \\
\text { understanding of probability distributions and } \\
\text { interpretation of p value associated with } \\
\text { statistics while Zoology students made } \\
\text { greater gains }\end{array}$ \\
\hline
\end{tabular}

\section{Methodology and Procedures}

The study adopted a two group non-equivalent design. Experimental and Control groups were assigned by simple random sampling. Both groups took a pre-test and a post-test, but only the Experimental group was treated (Creswell, 2009). The difference in the post-test scores between the two groups was compared. The treatment group was taught Heredity using Statistical concept instruction whilst the control group received instruction as usual.

The format for the research design is shown below: 
Table 1: The Format of the Research Design

\begin{tabular}{cccc}
\hline & Pretest & Treatment & Posttest \\
\cline { 2 - 4 } Treatment group & $\mathrm{O}_{1}$ & $\mathrm{X}_{1}$ & $\mathrm{O}_{2}$ \\
Control group & $\mathrm{O}_{1}$ & - & $\mathrm{O}_{2}$ \\
\hline
\end{tabular}

$\mathbf{0}_{1}=\quad$ is the first observation (pretesting) of Experimental and Control groups before treatment

$\mathrm{X}_{1}=$ Treatment

$\mathbf{0}_{2}=\quad$ is the second observation (post-testing) of experimental and Control groups after treatment

This type of research design enabled relevant information to be collected from the respondents through the use of Biology Achievement Test.

The research study was conducted at Malcolm Moffat College of Education. The College is one of the Teacher training colleges in Zambia. The research site is situated in Serenje urban area, two (2) kilometres from Serenje Town Centre in Central Province of Zambia. Malcolm Moffat College of Education was established in 1960 and is governed by the Council of Churches in Zambia. It is affiliated to the University of Zambia and the Ministry of Education, which underwrite its accreditation. Malcolm Moffat College of Education is chosen as a study site because that is where the problem under investigation is identified.

Heredity is a 12 hours topic taught in Third year. The activities involve solving genetic crosses, analyzing data, describing the distribution of quantitative traits, and allelic, genotypic, and phenotypic frequencies; and genetic mapping of eukaryotic chromosomes. Therefore, statistical concept to be taught will address concepts relevant to the analysis of genetic data, such as the basic laws of probability.

The target population of the study comprised all the Science students at Malcolm Moffat College Education enrolled in the year 2019 at Malcolm Moffat College of Education in Central Province. The total number of the target population was 256 of which 98 were females and 154 were males (College enrolment data, 2018). The sample constituted 93 third Year Biology students purposively selected from two intact classes A and B of which 45 students came from class A and 48 from Class B. The participants were identified for this study by using a purposive sampling technique, which assumes that a sample is selected "in a non-random manner, based on member characteristics relevant to the research problems." Purposive sampling was done because the two Classes were intact. Kombo and Tromp (2006: 82) state that, "the power of purposive sampling lies in selecting participants who will provide the richest information for in-depth analysis related to the central issue being studied. Later classes were assigned as either Experimental or Control using simple random probability.

Table 2: Distribution of Students from the sampled classes

\begin{tabular}{|l|c|c|c|}
\hline \multirow{2}{*}{ Classes } & \multicolumn{2}{|c|}{ Number of Students } & Total \\
\cline { 2 - 3 } & Male & Female & \\
\hline Experimental Class & 28 & 17 & 45 \\
Control Class & 34 & 14 & 48 \\
\hline
\end{tabular}

For the first two research questions, the researcher used Achievement Test which was given to both classes, $\mathrm{A}$ and B. Achievement Test was a test designed to measure the knowledge and proficiency of an individual or student in something that has been learned or taught.

The third research question required the use of a questionnaire. The questionnaires adopted a 5-point Likert scaling of Strongly Agree (SA), Agree (A) Undecided (U), Disagree (D) and Strongly Disagree (SD). These were ranked 5, 4, 3, 2 and 1 respectively. A questionnaire was administered to the both classes. Bryman (2006) contends that different research instruments are used in order to extend the breadth and range of inquiry.

Data were collected and the first and second hypotheses were tested with independent Sample T-test for the two groups set at 0.05 level of significance. Kpolovie (2011) affirmed that the Independent Sample T-test is the most suitable statistical tool for analysing and comparing the means of two separate groups while the third null hypothesis was tested using percentages.

\section{Presentation of Results}

The results are presented sequentially based on the research questions and hypotheses.

Table 3: T- test pre-test results of the Experimental and Control group before Treatment $(n=93)$

\begin{tabular}{|c|c|c|c|c|c|}
\hline Group & $\mathrm{N}$ & Mean $(\bar{x})$ & $\mathrm{df}$ & $\mathrm{t}-$ value & Sig. (2-tailed) \\
\hline Experimental group & 45 & 17.51 & & & \\
\hline Control group & 48 & 16.06 & 91 & 0.388 & 0.691 \\
\hline
\end{tabular}

\section{*Significant at $\mathbf{P}<0.05$}

The pre-test result subjected to t-test at 0.05 level of significance show that the value of $\mathrm{df}=91 \mathrm{p}=0.691$ $>\alpha=0.05$ i.e. Therefore, we fail to reject the null hypothesis. This implies that there was no significance difference between the Control group and the Experimental group in their entry behaviour before the treatment was applied to the Experimental Group. 


\subsection{Hypothesis Testing}

$\mathbf{H O}_{1}$ : There is no significant difference between the mean achievement scores of students who are taught by integrating statistical concept in the teaching of Heredity and those who are taught without integrating statistical concepts.

To test the hypothesis, the post-test performance scores of the experimental and control groups were subjected to independent Sample t- test. The result is shown in Table 4.

Table 4: The T-test Analysis comparing the effects of integrating statistical concepts on student teachers' Academic Achievement on Heredity after treatment $(n=93)$

\begin{tabular}{llllcll}
\hline Group & $\mathrm{N}$ & Mean $(\bar{x})$ & $\mathrm{df}$ & $\mathrm{t}-$ value & Sig. (2-tailed) & Decision \\
\hline Experimental group & 45 & 47.11 & & & & Sig. \\
Control group & 48 & 31.10 & & 3.485 & 0.001 & Reject H0 $_{1}$
\end{tabular}

\section{*Significant at $\mathbf{P}<0.05$}

From table 4 above the calculated value of $\mathrm{p}-$ value $=0.001$ is less than the $\alpha$ of 0.05 level and $\mathrm{df}=91$. Therefore, the null hypothesis was rejected. It is then clear that the academic achievement of students taught Heredity by integrating statistical concepts performed better than those taught using conventional method.

$\mathbf{H O}_{2}$ : There is no significant difference between the mean achievement scores of female students and male students on heredity in Biology.

To test null hypothesis 2 , the scores of the male and female students from both of the experimental group were subjected to Independent Sample t-test statistic. The summary of the analysis is presented in Table 5.

Table 5: A t-test analysis of the influence of gender on students' academic performance on Heredity $(n=$ 45)

\begin{tabular}{|c|c|c|c|c|c|c|}
\hline Group & $\mathrm{N}$ & Mean & df & $\mathrm{t}$ - value & Sig. (2-tailed) & Decision \\
\hline Male Exp. group & 28 & 27.79 & & & & Not Sig. \\
\hline Female Exp. group & 17 & 27.59 & 43 & 0.164 & 0.871 & Fail to reject $\mathrm{H} 01$ \\
\hline
\end{tabular}

\section{*Significant at $\mathbf{P}<0.05$ level of significance.}

From Table 5, the $\mathrm{df}=43 ; \mathrm{p}=0.871>\alpha=0.05$. This showed that there was no significant difference between the academic performance of male and female students taught by integrating the statistical concepts in the experimental group, hence, the null hypothesis was retained.

Research Questions 3: what is the effect of integrating statistical concepts on students' attitude towards heredity? The students were asked to respond to statements that would indicate their attitude toward Heredity after integrating statistical concepts in the teaching as shown in Table 6.

Table 6: Percentage Response of Students on their attitude towards genetics $(n=45)$.

\begin{tabular}{|l|l|l|l|l|l|l|}
\hline S/N & \multicolumn{1}{|c|}{ STATEMENT } & SA & A & UD & D & SD \\
\hline 1. & $\begin{array}{l}\text { After integrating statistical concepts in learning heredity, I can answer } \\
\text { questions on this topic with confidence }\end{array}$ & 31 & 45 & 24 & 00 & 00 \\
\hline 2. & $\begin{array}{l}\text { I am satisfied with the current curriculum for Biology Education at } \\
\text { College level without any statistical concepts }\end{array}$ & 2 & 7 & 9 & 53 & 29 \\
\hline 3. & $\begin{array}{l}\text { I recommend the integration of statistical concepts in the teaching and } \\
\text { learning of heredity in Biology }\end{array}$ & 31 & 47 & 22 & 00 & 00 \\
\hline 4. & $\begin{array}{l}\text { I have gained interest in heredity in Biology after integration of statistical } \\
\text { concepts }\end{array}$ & 27 & 49 & 13 & 7 & 4 \\
\hline 5. & $\begin{array}{l}\text { Integrating of statistical concepts has no impact on me } \\
\text { With the statistical concepts I have learnt, I can confidently teach heredity }\end{array}$ & 42 & 38 & 18 & 2 & 00 \\
\hline 7 & $\begin{array}{l}\text { With the knowledge I have acquired on heredity through integration of } \\
\text { statistical concepts, I can compete with others nationally and } \\
\text { internationally }\end{array}$ & 58 & 7 & 2 & 00 \\
\hline
\end{tabular}

\section{Source: Field data}

Data obtained from the questionnaire above, indicate that the students sampled had a generally positive perception of heredity after being taught by integrating statistical concepts. $76 \%$ of the students agreed that after integrating statistical concepts in learning heredity, they could answer questions on this topic with confidence while $82 \%$ also disagreed that they were satisfied with the current curriculum for Biology Education at College level without any statistical concepts.

Furthermore, $78 \%$ of the respondents recommend the integration of statistical concepts in the teaching and learning of heredity in Biology while only 79\% agreed that they had gained interest in heredity in Biology after integration of statistical concepts.

$90 \%$ disagreed with the statement that, integrating of statistical concepts had no impact on them. $80 \%$ of 
the respondents confessed that with the statistical concepts they had learnt, they said they were confident to teach heredity expeditiously and $91 \%$ boosted that with the knowledge they had acquired on heredity through integration of statistical concepts, they could not compete with others nationally and internationally.

\section{Discussion of Findings}

5.1 Effects of integrating statistical concepts on students' academic achievement on heredity in Biology Findings from this study showed that students taught by integrating statistical concepts in teaching or learning heredity in Biology had a mean score higher than those taught with conventional methods. The experimental group performed better than the control group. The hypothesis earlier posited was tested and the null hypothesis was rejected as the sample t-test had revealed a statistically reliable difference between the mean of the study group and control group respectively.

This finding is in agreement with that of Madlung et al. (2011) who suggested that Mathematics in Biology helped students effectively apply statistical data to interpret biological results and concepts. He further posited that integrating mathematical concepts into Biology courses offer students additional insight and probably provide a path to "extra sense", Darwin wished he had developed.

\subsection{Influence of gender on students' performance on heredity in Biology}

Null hypothesis two assessed whether there was significant difference in the academic performance of male and female students. This finding revealed that, there is no significance difference in male and female academic performance in Biology when taught by integrating statistical concepts. This shows that integrating statistical concepts in the teaching and learning of Heredity in Biology were gender friendly. That means that students' gender has no significant influence on their performance in genetics. Therefore, integrating statistical concepts method of instruction is effective in both male and female academic achievement.

The present finding supports that of Yusuf and Adigun (2010) who discounted the effect of gender on students' academic performance. This might be attributed to the fact that admission into the College involves criteria which hold no bias on the gender of the students to be admitted. The finding from this study implies that whether a student is male or female does not make a difference in his or her performance in the subject. This supports the call for more female students to take up courses such as genetic engineering that are traditionally known as 'male courses'. It also reinforces the call for equal chances in STEM areas for both male and female students.

This is in contrast to the works of Akinnubi et al. (2012) who reported that gender has influence on the performance of students in genetics. They remarked that female students usually have a better inclination to and quicker understanding of the concepts of Genetics than the male ones.

\subsection{Students' attitudes towards genetics after being taught integrating statistical concepts on Heredity in Biology}

Findings from this study indicate that students developed positive attitude to Biology after integrating statistical concepts in the teaching and learning of heredity. This is inconsonance with the findings of Samikwo (2013) but contradict the findings of Soyibo (1988), Abimbola (1998) and Skryabina (2000) who reported students have negative attitude towards genetics. The reason for the contradictory findings with reference to students' attitude may have been due to the fact that students who have a good attitude towards heredity also do better in Biology.

\section{Conclusion}

From the literature and researcher's own experience, it was clear that to truly integrate statistics and biology and engage students in the use of statistics in their learning of Biology, we would need to provide students with formal training in statistics as early as possible, give them the opportunity to practice the use of statistics, and demonstrate the importance of statistical data analysis in biological research. We can therefore conclude that;

1. The academic performance of students taught Heredity by integrating statistical concepts perform better than those taught using conventional methods.

2. That integrating statistical concepts method of instruction is gender friendly and effective in both male and female academic achievement.

The attitude of students towards Heredity questions has been improved by integrating statistical concepts

\section{References}

Abimbola, I.O. (1998). Teachers' Perceptions of Important and Difficult Content in Biology.Journal of Functional Education, 1 (1), 10-12.

Akinnubi, R. T., Oketayo, O. O., Akinwande, D. D. and Ifedayo, O. A. (2012). Student- Lecturer Variables and Low Performance of Students' in Genetics: A Case Study of Course in Adeyemi College of Education, Ondo State, Nigeria. Journal of Research in Education and Society 3 (2), 78-82. 
Bryman, A.(2006). Integrating quantitative and qualitative research: How is it done? Qualitative Research, 6, 97 $-113$.

Cochran, K. F., DeRuiter, J. A., and King, R. A. (1993). Pedagogical content knowing: an integrative model for teacher preparation. Journal of Teacher Education 46 44(4), 263-272.

Cohen, J.SE.(2004). Mathematics is biology's next microscope only better; biology is mathematics next physics only better. PLoS Biology, 12:2017-2023.

Creswell, J.W., 2003. Research Design Qualitative, Quantitative and Mixed Methods Approaches. 2nd ed. Thousand Oaks: SAGE Publications.

Elser, J., \& Hamilton, A. (2007). Stoichiometry and the new biology: the future is now. PLoS Biology, 5(7). https://doi.org/10.1371/journal.pbio.0050181

Examinations Council of Zambia (2017).School Certificate and GCE Examiner's Reports for October/November 2017 Examinations. Lusaka: ECZ.

Jungck JR. (1997). Ten equations that changed biology: Mathematics in problem- solving biology curricula. Bioscience 23: 11-36.

Kasongo \& Samuel (2018). Impact of reducing Mathematics component in O-level Biology- A case of Colleges of Education in Mansa.

Kombo, D.K. \& Tromp, L.A. (2006). Proposal and Thesis writing: An introduction. Nairobi: Paulines Publication Africa.

Kpolovie, P. J. (2011). Statistical Techniques for Advanced Research. Owerri: Springfield Publishers

Leach, J. \& Scott, P. (2003). Individual and sociocultural views of learning in science education. Science \& Education, 12(1), 91-113.

Meleka \& Samuel (2018) The Significance of Statistics in Undergraduate Biology Education - A case of CBU.

Robeva R. \& Laubenbacher R.(2009). Mathematical biology education: beyond calculus. Science. 325:542-543.

Samikwo, D. C. (2013) Factors Which Influence Academic Perfomance In Biology In Kenya: A

Perspective For Global Competitiveness. International Journal of Current Research, 5 (12), 4296-4300.

Skryabina, E. (2000). Student Attitudes to Learning Biology and Physics at School and University Levels in Scotland. PhD Thesis, University of Glasgow.

Soyibo, K. (1988a). An Analysis of Some Biology Teachers Knowledge of Misconception of Selected

Biology Concepts. A paper presented at WAEC monthly seminar 30th Jan. Sub-degree (2003-2006). University of Ilorin, Ilorin, Nigeria.

Yusuf, M. A. and Adigun, J. T. (2010). The Influence of School Sex, Location and Type on Students' Academic Performance. International Journal of Education Science, 2(2): 81-85

\section{Acknowledgement}

We thank the Almighty God and people whose help made this work possible. We would also like to show our gratitude to the teaching staff at Copperbelt University for the support they gave us throughout the program. We would especially like to thank our amazing lecturers for their knowledge and guidance through the process.

To our lovely wives and children we thank them for their love and support during this period. Lastly, we are highly indebted to the Principal, the Registrar, College Chaplain and the entire staff of Malcolm Moffat College of Education, for allowing us carry out the research with warm reception. We extend our gratitude to Head of Section and all respondents from the Science Section for their active participation during data collection. The source of data is a Master's thesis that was conducted in partial fulfillment for the award of Master of Science in Biology Education of the Copperbelt University in Zambia. The research article has not been published anywhere else. 